\title{
Microstructure and Magnetic Properties of the Nanocrystalline Fe-Co-Zr-Ti-Pr-B Alloys
}

\section{P. PAWLIK}

Institute of Physics, Czȩstochowa University of Technology

Al. Armii Krajowej 19, 42-200 Częstochowa, Poland

Investigation of the $\mathrm{Fe}_{60} \mathrm{Co}_{13} \mathrm{Zr}_{1} \mathrm{Ti}_{3} \mathrm{Pr}_{9} \mathrm{~B}_{14}$ alloy $1 \mathrm{~mm}$ diameter rods and $3 \mathrm{~mm}$ outer diameter tubes showed a possibility of processing nanocrystalline magnets by direct quenching. It was revealed that the low temperature annealing of the tube samples at $573 \mathrm{~K} / 10 \mathrm{~min}$ resulted in an improvement of the intrinsic coercivity that reaches $\approx 1260 \mathrm{kA} / \mathrm{m}$, which was a similar value to that measured for thin ribbon annealed at $973 \mathrm{~K} / 10 \mathrm{~min}$. The $\mathrm{X}$-ray diffraction analysis revealed that the hard magnetic $\operatorname{Pr}_{2}(\mathrm{Fe}, \mathrm{Co})_{14} \mathrm{~B}$ was the single crystalline phase that precipitated during rapid solidification process of the tube and rod samples and during devitrification annealing of the ribbons.

PACS numbers: 75.50.Ww, 75.50.Kj, 71.20.Eh

\section{Introduction}

Over last few years, studies of Fe-Co-RE-B-type $(\mathrm{RE}=\mathrm{Nd}$, Pr, Dy) bulk glassy alloys were intensified due to the possibility of processing nanocomposite magnets by subsequent devitrification annealing [1-3]. It was shown that admixture of 1 at.\% of $\mathrm{Zr}$ to $(\mathrm{Fe}, \mathrm{Co})_{73.5} \mathrm{Zr}_{1}(\mathrm{Pr}, \mathrm{Dy})_{4.5} \mathrm{~B}_{20}$-type alloys allows to fabricate bulk amorphous samples in a form of $1 \mathrm{~mm}$ diameter rods and 1, 2, and $3 \mathrm{~mm}$ outer diameter (o.d.) thin walled tubes by suction-casting technique $[4,5]$. Due to relatively low volume fraction of hard magnetic phase rather moderate values of coercivity ${ }_{\mathrm{J}} H_{\mathrm{c}}$ up to $\approx 180 \mathrm{kA} / \mathrm{m}$ and $(B H)_{\max }$ of $\approx 47 \mathrm{~kJ} / \mathrm{m}^{3}$ were measured [5].

An investigation of strip-cast $\mathrm{Nd}-\mathrm{Fe}-\mathrm{B}-\mathrm{Ti}-\mathrm{C}$ alloys (with thickness $t \approx$ $100 \mu \mathrm{m}$ ), containing $\approx 8.5-9$ at.\% of $\mathrm{Nd}$, showed good hard magnetic properties and nanocrystalline microstructure in the as-cast state [6]. Recent studies of bulk directly quenched $\mathrm{Fe}_{60} \mathrm{Co}_{13} \mathrm{Zr}_{1} \mathrm{Ti}_{3} \mathrm{Pr}_{9} \mathrm{~B}_{14}$ alloy [7] showed a possibility of processing nanocrystalline samples in a form of $1 \mathrm{~mm}$ diameter rods and up to $3 \mathrm{~mm}$ o.d. thin walled tubes by the suction-casting technique. Moreover, the 
microstructure of thick ribbons $(t>100 \mu \mathrm{m})$ appeared to be a mixture of amorphous and nanocrystalline phases. Relatively high values of ${ }_{\mathrm{J}} H_{\mathrm{c}}$ of $\approx 780 \mathrm{kA} / \mathrm{m}$ and $1240 \mathrm{kA} / \mathrm{m}$ were measured, respectively, for the tube and ribbon samples in the as-cast state. This has led to the present studies of devitrification annealing effect on the microstructure and magnetic properties of fully amorphous thin ribbon samples $(t \approx 20 \mu \mathrm{m})$. Furthermore, additional low temperature annealing effect on the magnetic properties of directly-quenched nanocrystalline samples was discussed. The comparison of the magnetic properties of all investigated samples was also presented in the paper.

\section{Experimental, results, and discussion}

Ingot samples of the $\mathrm{Fe}_{60} \mathrm{Co}_{13} \mathrm{Zr}_{1} \mathrm{Ti}_{3} \mathrm{Pr}_{9} \mathrm{~B}_{14}$ alloy were produced by arc-melting under an Ar atmosphere of the high purity (99.99\%) constituent elements with addition of pre-alloyed $\mathrm{Fe}-\mathrm{B}$ of known composition. The ribbon samples of various thicknesses (from $20 \mu \mathrm{m}$ to $180 \mu \mathrm{m}$ ) were melt-spun by varying the linear speed of the copper block surface (from $25 \mathrm{~m} / \mathrm{s}$ down to $6 \mathrm{~m} / \mathrm{s}$ ). The bulk samples in a form of $1 \mathrm{~mm}$ diameter rods and $3 \mathrm{~mm}$ o.d. tubes were produced by the suction-casting technique. The phase composition of the samples was examined by the X-ray diffractometer with Co $K_{\alpha}$ radiation. The bulk samples were crushed to powder in order to obtain specimens representative of the entire volume of rods and tubes, in each case. Devitrification annealing of the amorphous ribbon samples was performed at various temperatures around the crystallization temperature $T_{\mathrm{x}}$ to reach best magnetic properties. The magnetic measurements were carried out using a vibration sample magnetometer in external magnetic fields up to $5 \mathrm{~T}$.

$\mathrm{X}$-ray diffraction (XRD) traces detected for the as-cast samples in a form of: melt-spun thin and thick ribbons and suction-cast $1 \mathrm{~mm}$ diameter rods and $3 \mathrm{~mm}$ o.d. tubes are shown in Fig. 1a. It was shown that thin ribbons $(t<70 \mu \mathrm{m})$ were fully amorphous, while ribbons thicker than $100 \mu \mathrm{m}$ contained nanocrystalline phase identified as the $\operatorname{Pr}_{2}(\mathrm{Fe}, \mathrm{Co})_{14} \mathrm{~B}$ hard magnetic phase, embedded within an amorphous matrix. The X-ray diffraction analysis performed for both as-cast rod
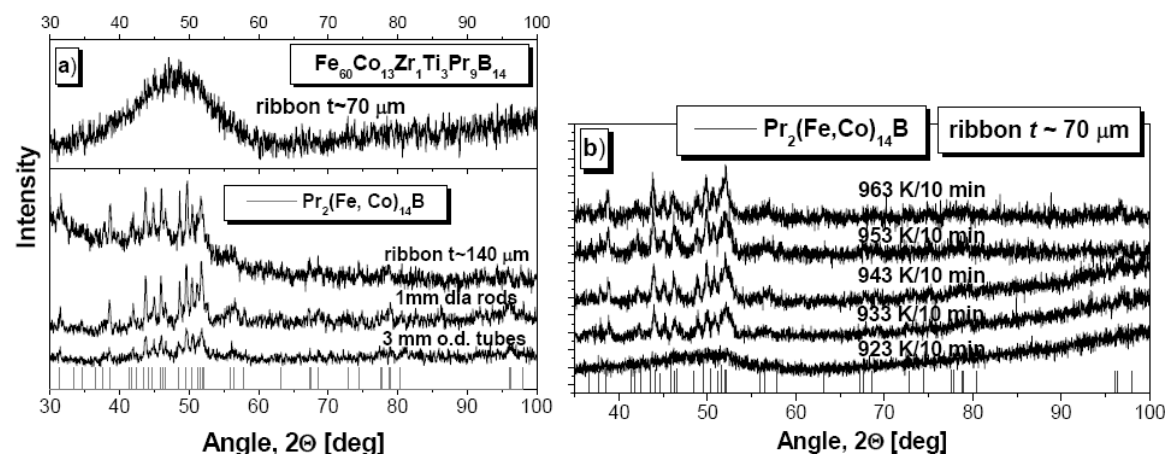

Fig. 1. XRD traces for the $\mathrm{Fe}_{60} \mathrm{Co}_{13} \mathrm{Zr}_{1} \mathrm{Ti}_{3} \mathrm{Pr}_{9} \mathrm{~B}_{14}$ alloy as-cast ribbon, $1 \mathrm{~mm}$ diameter rods and $3 \mathrm{~mm}$ o.d. tubes (a), and thin ribbon annealed at various temperatures (b). 
and tube samples also revealed the presence of the $\operatorname{Pr}_{2}(\mathrm{Fe}, \mathrm{Co}){ }_{14} \mathrm{~B}$ nanocrystalline phase. Transmission electron microscopy (TEM) images of the as-cast tube specimens presented in [7] showed heterogeneous mixture of large crystallites (diameter of $\approx 250 \mathrm{~nm}$ ) and agglomerates of small nanocrystallites (diameter $<10 \mathrm{~nm}$ ). Subsequent low temperature annealing of the tube samples (at $573 \mathrm{~K}$ and $673 \mathrm{~K}$ for $10 \mathrm{~min}$ ) did not result in any change of their phase composition. However, a significant rise of the coercive field after heat treatment was observed (Fig. 2a). As the $\operatorname{Pr}_{2}(\mathrm{Fe}, \mathrm{Co})_{14} \mathrm{~B}$ phase precipitated during rapid solidification process (Fig. 1a) and the annealing temperature is far below the crystallization temperature, therefore one can expect the presence of some structural relaxation of $\operatorname{Pr}_{2}(\mathrm{Fe}, \mathrm{Co})_{14} \mathrm{~B}$ hard magnetic phase stimulated by heat treatment. The differential scanning
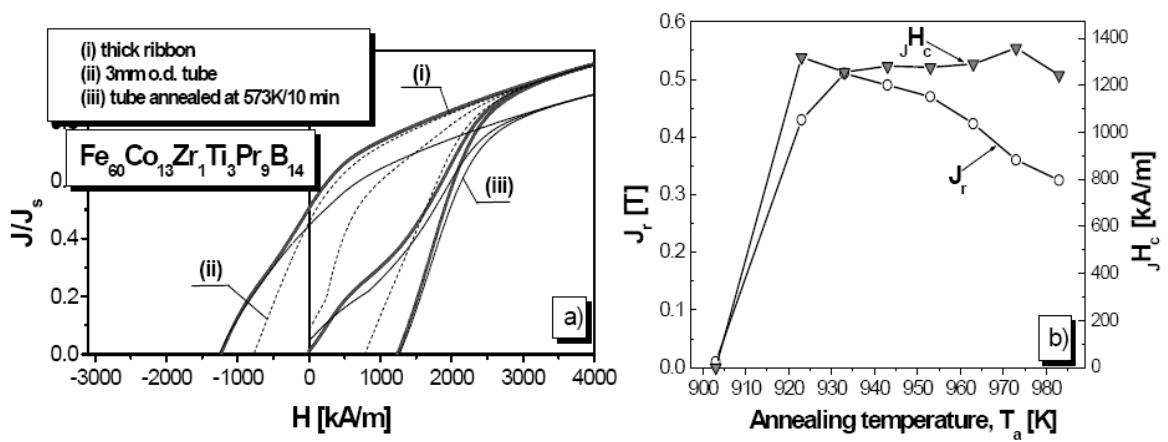

Fig. 2. (a) Hysteresis loops measured for the $\mathrm{Fe}_{60} \mathrm{Co}_{13} \mathrm{Zr}_{1} \mathrm{Ti}_{3} \mathrm{Pr}_{9} \mathrm{~B}_{14}$ alloy: as-cast thick ribbon (i), as-cast $3 \mathrm{~mm}$ o.d. tube (ii) and $3 \mathrm{~mm}$ o.d. tube annealed at $573 \mathrm{~K} / 10 \mathrm{~min}$ (iii); (b) remanence $J_{\mathrm{r}}$ and coercivity ${ }_{\mathrm{J}} H_{\mathrm{c}}$ dependences on the annealing temperature $T_{\mathrm{a}}$ for the $\mathrm{Fe}_{60} \mathrm{Co}_{13} \mathrm{Zr}_{1} \mathrm{Ti}_{3} \operatorname{Pr}_{9} \mathrm{~B}_{14}$ alloy thin ribbon samples.

calorimetry (DSC) analysis allowed to determine the glass transition temperature $T_{\mathrm{g}} \approx 890 \mathrm{~K}$ and crystallization temperature $T_{\mathrm{x}} \approx 923 \mathrm{~K}$ of the amorphous phase. This allowed to specify the annealing conditions to create nanocrystalline microstructure by devitrification of the amorphous ribbons. Consequently, the $20 \mu \mathrm{m}$ thick amorphous ribbon samples were annealed at various temperatures $T_{\mathrm{a}}$ from $903 \mathrm{~K}$ to $973 \mathrm{~K}$ for $10 \mathrm{~min}$. XRD performed for annealed ribbon samples proved nanocrystalline microstructure of all samples annealed above the $T_{\mathrm{x}}$ (Fig. 1b). The investigated samples contained 2-14-1 hard magnetic phase embedded within the amorphous matrix. It was shown in Fig. $2 \mathrm{~b}$ that with increase in $T_{\mathrm{a}}$ above $933 \mathrm{~K}$, the ${ }_{\mathrm{J}} H_{\mathrm{c}}$ raises up to $1360 \mathrm{kA} / \mathrm{m}$, while the $J_{\mathrm{r}}$ decreases from $0.51 \mathrm{~T}$ for $T_{\mathrm{a}}=933 \mathrm{~K}$ to $0.36 \mathrm{~T}$ for $T_{\mathrm{a}}=973 \mathrm{~K}$. The highest ${ }_{\mathrm{J}} H_{\mathrm{c}}$ value $(\approx 1360 \mathrm{kA} / \mathrm{m})$ measured for the annealed ribbons was comparable to those measured for as-cast nanocrystalline ribbons as well as for the tubes annealed at $573 \mathrm{~K} / 10 \mathrm{~min}$. 


\section{Conclusions}

It was shown that the low temperature annealing of the nanocrystalline $3 \mathrm{~mm}$ o.d. tube samples resulted in significant improvement of the coercive field of the samples. The X-ray diffraction analysis allowed to determine the phase composition of the as-cast tube samples, that consists of the $\operatorname{Pr}_{2}(\mathrm{Fe}, \mathrm{Co}){ }_{14} \mathrm{~B}$ hard magnetic phase embedded within the amorphous matrix. For the annealed tubes no change of the phase composition was detected, while significant rise of ${ }_{\mathrm{J}} H_{\mathrm{c}}$ was measured. The grain growth during heat treatment has to be excluded as an origin of the rise of coercive field, as one can expect rather reduction of coercivity with the increase in the grain size [8]. This indicated presence of some structural relaxations of the $\operatorname{Pr}_{2}(\mathrm{Fe}, \mathrm{Co})_{14} \mathrm{~B}$ phase during heat treatment. In bulk as-cast samples the hard magnetic phase precipitated during rapid quenching, which may result in certain distortion of the lattice parameters of the hard magnetic phase and eventually affect the magnetic properties of the samples. Similar phase composition as well as the magnetic properties were detected for the thin ribbon samples annealed around the crystallization temperature $T_{\mathrm{x}}=923 \mathrm{~K}$. The maximum coercive field of $\approx 1360 \mathrm{kA} / \mathrm{m}$ measured for the ribbon annealed at $973 \mathrm{~K} / 10 \mathrm{~min}$ is comparable to these measured for the low temperature annealed nanocrystalline tubes and as-cast nanocrystalline ribbon samples.

\section{Acknowledgments}

Work supported by the Polish Ministry of Education and Science (grant no. 3T08A 06327$)$.

\section{References}

[1] W. Zhang, M. Matsusita, C. Li, K. Kimura, A. Inoue, Mater. Trans. JIM 42, 2059 (2001).

[2] W. Zhang, M. Matsusita, A. Inoue, Mater. Trans. JIM 42, 1543 (2001).

[3] W. Zhang, A. Inoue, J. Appl. Phys. 91, 8834 (2002).

[4] P. Pawlik, M. Marinescu, H.A. Davies, N.J. Harrison, I. Todd, J.J. Wyslocki, in: Proc. 18th Int. Workshop on High Performance Magnets and their Applications, Annecy (France) 2004, Eds. N.M. Dempsey, P. de Rango, CD-ROM by O. Cugat, C. Chille, Annecy 2004, p. 601.

[5] P. Pawlik, H.A. Davies, W. Kaszuwara, J.J. Wysłocki, J. Magn. Magn. Mater. 290-291, 1243 (2005).

[6] S. Hirosawa, H. Kanekiyo, Y. Shigemoto, T. Miyoshi, in Ref. [4], p. 655.

[7] P. Pawlik, K. Pawlik, H.A. Davies, W. Kaszuwara, J.J. Wysłocki, N. Harrison, I. Todd, J. Alloys Comp. 423, 99 (2006).

[8] A. Mager, Ann. Phys. (Germany) 11, 15 (1952). 